\title{
The Effect of Transcranial Direct Current Stimulation on Smartphone Addiction and Stress: a randomized controlled study
}

\author{
Eunsang Lee \\ aDepartment of Physical Therapy, Gwangju Health University, Gwangju, Republic of Korea
}

Objective: Smartphone addiction can cause forward head posture, carpal tunnel syndrome and depression, and anxiety. Various interventions have been proposed to resolve Smartphone addiction. However, research regarding the efficacy of these interventions remains lacking. This study was conducted to investigate the effect of tDCS (Transcranial Direct Current Stimulation) on smartphone addiction solution and stress reduction.

Design: A randomized controlled trial.

Methods: The participants were divided randomly into two group (tDCS vs. Control). tDCS was applied to 41 adults (22.95 \pm 2.76 years). The tDCS group was applied $2 \mathrm{~mA}$, for 13 minutes twice over a 26 minute period $\left(\mathrm{n}_{1}=21\right)$. The control $\left(\mathrm{n}_{2}=20\right)$ was not applied after padding and was applied twice for 13 minutes over a 26 minute period. This study was conducted four times a week for a total of four weeks.

Results: Smartphone addiction for tDCS showed significant improvement in the results in the S-score $(\mathrm{p}<0.05,95 \% \mathrm{CI}: 0.702$, 4.922), and the result of heart rate (HR) and skin conductivity (SC) to stress. The tDCS group and control group showed no significant decrese in the results in the HR ( $p>0.05,95 \%$ CI: $-3.390,8.332$ ), but tDCS group showed significant decrese in the results in the $\mathrm{SC}(\mathrm{p}<0.05,95 \% \mathrm{CI}$ : $0.060,1.343)$

Conclusions: This study suggected that smartphone addiction treatment and decreses of stress. The use of tDCS will reduce the addiction rate of adults and reduce stress, so that possible side effects in society can be solved.

Key Words: Addictive, Smart phone, Stress, Transcranial Direct Current Stimulation

\section{서론}

스마트폰(Smartphone)은 1992년을 기준으로 현대사 회에 빠르게 자리매김하였고, 스마트폰 보유율은 $94.8 \%$ 에 달하고 있다 $[1,2]$. 스마트폰은 음성통화 뿐 아니라 정보검 색과 공유, SNS (Social Network Service)을 활용한 유대 활동 등 $\mathrm{PC}$ 를 대신하여 우리생활에서 없어서는 안 될 필 수품이 되었고[3], 과학기술정보통신부와 한국정보화진흥 원 [2]에 따르면 성인의 $18.1 \%$ 에서 과의존율을 보인다고 보고 하였다. 스마트폰 과의존율의 증가로 없으면 불안해 지는 스마트폰 중독의 위험이 증가 하고 있다.

스마트폰 중독이란 스마트폰 과다 사용으로 금단과 내 성과 함께 일상생활 장애를 유발시킬 수 있는 상태라고 정
의할 수 있으며[4], 스마트폰 중독은 인터넷과 휴대전화 중 독이 결합되어 $\mathrm{PC}$ 기반 인터넷 사용보다 높은 중독성을 보 이고 있다 $[5,6]$. 이런 스마트폰 중독은 신체적으로 거북목 증후군, 손목터널 증후군과 협착성 윤활막염 등을 일으킬 수 있으며, 정신적 문제로는 강박증, 우울, 불안과 상실, 무시, 수면장애와 집중력 저하를 일으킬 수 있다[7, 8]. Baumeister와 Heatherton[9]의 연구에 의하면 스마트폰 중독은 자기 조절 기능이 약화되는데 사람들은 더 감정적 으로 반응하거나 짜증내며 스트레스와 연관된다고 하였으 며, 심미영 등 [10]은 스마트폰 중독이 정신적 스트레스에 직접적인 상관성을 보이며 스트레스와도 밀접한 상관성을 보이고 있다.

이런 스마트폰 중독을 해소하기 위해 지속적인 연구가

Received: Mar 2, 2021 Revised: Mar 11, 2021 Accepted: Mar 15, 2021

Corresponding author: Eunsang Lee (ORCID https://orcid.org/0000-0002-9763-2439)

Department of Physical Therapy, Gwangju Health University, 73, Bungmun-daero 419beon-gil, Gwangsan-gu, Gwangju, Republic of Korea Tel: (82 for International)-062-958-7649 Fax:062-958-7768 E-mail: eslee@ghu.ac.kr

This is an Open-Access article distributed under the terms of the Creative Commons Attribution Non-Commercial License (http://creativecommons.org/licenses/ by-nc/4.0) which permits unrestricted non-commercial use, distribution, and reproduction in any medium, provided the original work is properly cited. Copyright (c) 2021 Korean Academy of Physical Therapy Rehabilitation Science 
진행되고 있으며 인지-행동치료[11], 약물(bupropion)[12], 모래놀이 치료[13], 인터넷 사용 프로그램[14] 등 다양한 방법들이 사용되고 있다. 그러나 대부분의 방법들이 시간 과 비용면에서 많은 투자가 필요하며, 비용과 시간의 효율 성을 따져봤을 때 쉽게 접근하기 힘들며 효율성 또한 의문 적이다.

중독은 생리학적으로 앞이마엽뒤가쪽피질(Dorsolateral prefrontal cortex; DLPFC)이 갈망증상으로 이어져 중독 에 주요한 역할을 하고 있다고 알려졌다[15]. 최근 DLPFC 를 통한 중독증상 완화에 대한 연구가 활발히 진행되고 있 으며[16], Eichhammer 등 [17]의 연구에 따르면 DLPFC 에 고주파수로 자극했을 때 욕구가 줄어드는 것을 확인했 다. 선행연구들을 종합해 봤을 때 주로 스마트폰 중독에 대 한 연구들은 신체적 활동과 정서적 활동을 중재로 하여금 스마트폰 중독을 해소하고자 하였으며, 아직까지 다른 중 독의 치료를 위해 뇌과학적 연구가 진행되어 왔지만 스마 트폰 중독에 대한 뇌 과학적 중재방법에 대한 연구는 아직 까지 진행되고 있지 않다.

일반적으로 뇌를 부분적으로 자극할 수 있는 방법은 경 두개 자기자극(Repetitive transcranial magnetic stimulation; rTMS)과 경두개 직류자극(Transcranial direct current stimulation; tDCS)을 사용할 수 있다. 그 중rTMS는 비용 적인 측면과 장비의 희소성, 의료기기로서 병원에 방문해 야 하는 여러가지 문제 때문에 스마트폰 중독 환자들이 접 근하기 쉽지 않다. 그러나 $\mathrm{tDCS}$ 는 두피에 위치한 두 개의 전극간 발생하게 되는 미세 직류전류로 뇌의 겉질을 활성 또는 감소시키는 뇌 자극 방법으로 다른 중재와는 다르게 비교적 간단하고 비 침습적이기도 하며 비용적인 측면에 서 효율적으로 사용되고 있다[17].

따라서 본 연구에서는 선행연구를 참고하여 $\mathrm{tDCS}$ 가 스 마트폰 중독 감소에 효과를 가져올 것이라는 가설을 설정 하고 스마트폰 중독 감소로 인해 스트레스 또한 감소할 것 이다라는 가설을 설정하였으며, 실험을 실시하여 검증하 고자 한다.

\section{연구 방법}

\section{연구 설계}

본 연구는 $\mathrm{tDCS}$ 가 성인의 스마트폰 중독에 미치는 효 과를 알아보기 위해 유사 실험 연구로, 두 집단의 사전·후 설계 방법을 사용하였다. 대상자에게 단일 눈가림법을 사 용하였으며, $\mathrm{S}$ 척도 기준 '잠재적 위험 사용자군' 미만인 자는 제외하였고, 실험에 동의한 45 명을 대상으로 실험 을 진행하였다. 대상자는 $\mathrm{tDCS}$ 적용군, 대조군으로 각 23 명과 22명으로 분류하였다. 치료 프로그램으로 각 그 룹은 총 4 주 동안 주4회, 총 16 회의 중재를 적용한 후, 각
그룹의 중재 효과를 비교하기 위해 사전, 후 모두 $\mathrm{S}$ 척도와 Procomp infiniti (Biofeedback; Thought technology Ltd, Canada)을 사용해 검사를 실시하였다.

\section{연구 대상}

본 연구는 $\mathrm{G}$ 광역시에 위치한 ' $\mathrm{G}$ '대학교에 재학 중인 성인을 대상으로 모집 하였다. 연구 진행에 관련된 설명을 자세히 듣고 참여 의사를 밝힌 대상자 총59명을 모집하였 으며, 선정조건을 충족시키지 못한 14 명을 제외하고 총 45 명의 대상자로 진행하였다.

선행연구를 참고하여 연구대상자의 선정 조건을 설정 하였으며 다음과 같이 설정하였다[18]. 1. tDCS 부작용을 초례할 수 있는 뇌 손상 경험이 있는 사람, 2. 시각 또는 지 각에 문제가 있는 사람, 3 . 운동과 감각 기능에 이상이 있 는 사람, 4. 머리 안에 금속 삽입물이 있는 사람, 4. S척도 '잠재적 위험 사용군(40점 이상)'에 해당하지 않는 자를 제 외한 45명의 대상자를 선정하였다. 무작위 배정을 위해 컴 퓨터프로그램(Random Allocation Software 2.0, Isfahan University, Iran)을 사용하여 모집된 대상자를 배정한 결 과 tDCS그룹에 23명(남: 11, 여: 12), 대조그룹에 22명(남: 10 , 여: 12)으로 배정 되었으며, 중도탈락(tDCS그룹 남2, 대조그룹 남1, 여 1 ; 총 4명)을 제외한 41명으로 실험을 진 행하였다. 실험 전 대상자들에게 실험에 대한 충분한 이해 와 설명을 하였고, 자발적 참여 의사를 밝힌 대상자들에게 실험 참여 동의서에 서명 후 헬싱키선언에 따른 윤리기준 에 준수하여 연구를 진행하였다. 연구 대상자의 일반적 특 성은 다음과 같다(Table 1).

\section{중재방법}

\section{경피두개 직류자극(Transcranial direct currentstimulation; tDCS)}

tDCS 중재는 미국의 식품 의약국(FDA)에서 안정성을 승인 받은 The Brain Driver tDCS v2.1 (v2.1; The Brain Driver Inc., USA)를 사용하였다. 이마에 부착하는 전극은 원형모양 $5 \times 5$ 크기의 패드를 이용하는 전극을 사용했다. 모든 스펀지 패드는 $0.9 \%$ 생리식염수를 충분히 뿌린 후 헤 어밴드를 사용하여 대상자에 적용 부위에 맞게 고정 하였 고, 대상자가 편안하다고 생각하는 자세로 누워 시행 하였 다(Figure 1). 전극 배치와 강도는 선행 연구에 맞춰 진행 하였다. 국제 10-20 EEG기록법에 의거하여 앞이마겉질에 해당하는 좌측(F3)과 우측(F4)에 적용하였다(Figure 1A). 본 중재가 이루어지는 동안 편하게 쉬도록 하였으며, 강도 는 $2 \mathrm{~mA}$ 로 13 분씩 2 번, 1 주일에 4 회, 4 주동안 총 16 회를 적용하였다[19]. 
Table 1. General Characteristics of Participants

$(\mathrm{n}=41)$

\begin{tabular}{llll}
\hline Characteristics & $\begin{array}{l}\text { tDCS group } \\
\left(\mathbf{n}_{\mathbf{1}}=\mathbf{2 1}\right)\end{array}$ & $\begin{array}{l}\text { Control group } \\
\left(\mathbf{n}_{\mathbf{2}}=\mathbf{2 0}\right)\end{array}$ & $\mathbf{t} / x^{2}(\mathbf{p})$ \\
\hline Gender (male / female) & $9 / 12$ & $9 / 11$ & $0.019(0.890)$ \\
Age (years) & $22.62(1.99)^{\mathrm{a}}$ & $23.30(3.40)$ & $-0.787(0.436)$ \\
Height (cm) & $167.33(9.97)$ & $165.20(8.30)$ & $0.743(0.462)$ \\
Weight (kg) & $63.24(7.79)$ & $59.95(11.55)$ & $0.791(0.434)$ \\
S-Score baseline (point) & $44.10(2.91)$ & $43.80(2.65)$ & $0.339(0.736)$ \\
\hline
\end{tabular}

The values are presented mean (SD) ${ }^{\mathrm{a}}$

tDCS: transcranial direct current stimulation.

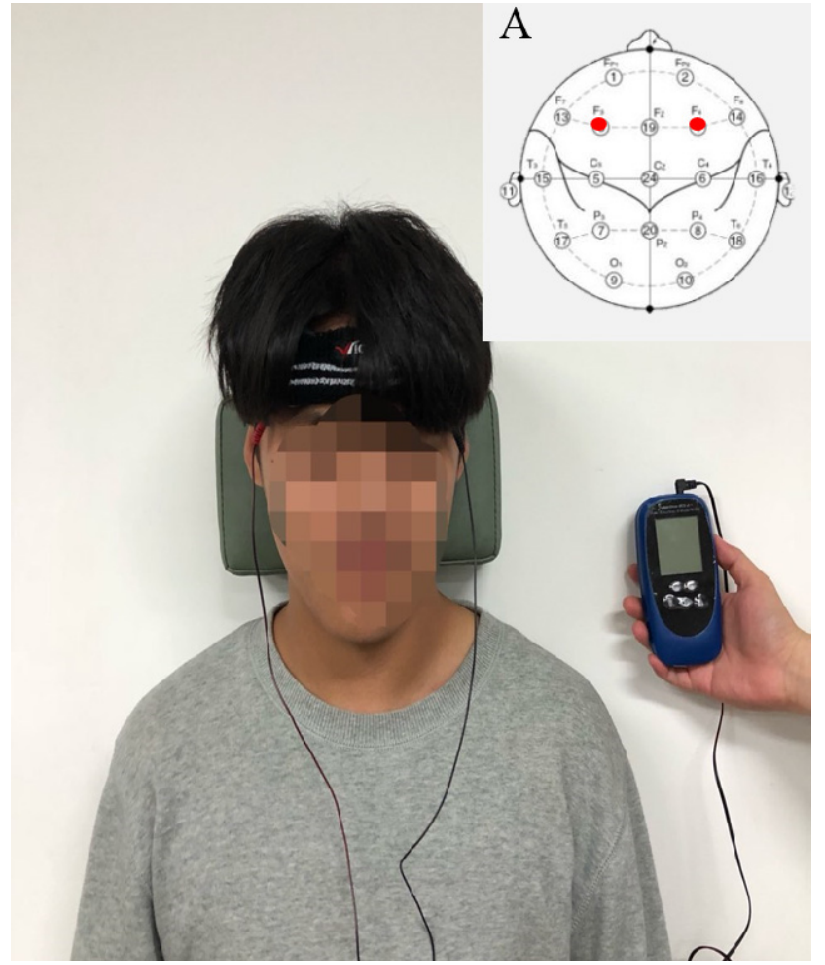

Figure 1. Application of tDCS and pad attaching area (A) pad attaching area $\mathrm{F}_{3}$ and $\mathrm{F}_{4}$

\section{대조군(Control)}

대조군은 플라시보 효과(Placebo effect)를 사용한 중재 를 적용 하였으며, 중재는 The Brain Driver tDCS (v2.1; The Brain Driver Inc., USA)를 사용하였다. 피부에 부착 하는 전극은 스펀지 재질인 원형모형 $5 \times 5$ 크기의 패드 전 극을 사용했다. 패드는 $0.9 \%$ 생리식염수를 충분히 뿌린 후 헤어밴드로 대상자에 맞게 고정하였고, 대상자가 편안하 게 누운 자세로 대상자에게 "시작합니다" 라는 내용을 전 달하였지만 장치의 중재는 이루어 지지 않았다. 대조군은 실험군과 같이 자극 시간은 13 분, 2 번씩, 1 주일에 4 회, 4 주 총 16 회를 적용 하였다.

\section{측정방법 및 도구}

\section{스마트폰 중독 척도( $S$ 척도)}

본 연구에서 스마트폰 중독의 정도를 알아보기 위해 2011년 한국정보화진흥원에서 개발한 성인용 $\mathrm{S}$ 척도를 사 용했다. 점수가 높을수록 중독의 정도가 심한 것을 의미한 다. $\mathrm{S}$ 척도의 구성은 총 15 문항으로 1 요인 일상생활장애 $(15,12,9,5,1$ 번), 3요인 금단( $14,11,8,4$ 번), 4요인 내성 $(13,10,7,3$ 번)으로 구성되어 있으며, 15 문항 중 12 문항 $(1,2,3,5,6,7,8,9,11,12,13,14$ 문항)은 전혀 그렇지 않다 1점, 그렇지 않다 2점, 그렇다 3점, 매우 그렇다 4점을 부여하고 나머지 3 문항( $4,10,15$ 문항)은 역 채점을 실시 하여 총점을 추출하였으며 $\mathrm{S}$ 척도의 Cronbach's $\alpha$ 는 .846 로 높은 신뢰도를 보였다[5].

\section{스트레스(Stress)}

심박수와 피부전도도의 측정은 Procomp infiniti (Biofeedback; Thought technology Ltd, Canada)를 이용하 였다. 피부전도(Skin conductance, SC)의 단위는 microsecond $(\mu \mathrm{s})$ 이고, 심박동수(heart rate, HR)의 단위는 beat $/ \mathrm{min}$ 이다.

Pro-Comp Infiniti는 새로운 8채널, 컴퓨터화된 바이오 피드백과 임상 환경에서 데이터 획득에 필요한 전력과 유 연성을 갖춘 다중 양식 인코더를 사용하였다.

측정방법은 피부전도는 오른검지와 오른새끼손가락에 피부전도센서를 부착하며 심박수는 오른손중지에 심박센 서를 부착하여 최대한 안정되고 편안한 자세로 앉아서 5 분 동안 측정하였다.[20]

피부의 접촉저항 최소화를 위해 알코올 솜으로 손가락 표면을 닦아내면서 불필요한 노이즈를 차단하였다. 측정 전 신체적, 심리적 안정을 위하여 안정된 측정 환경에서 10 분간 안정을 취하였다. 환경은 최대한 소음이 없고 습도 와 온도를 일정하게 유지시키고 시각적 자극을 피하기 위 해 안대를 사용하였다. 


\section{자료 분석}

연구의 모든 통계는 SPSS Ver. 20(Ver. 20; SPSS Inc., USA)프로그램을 사용하여 평균과 표준편차를 산출하였 다. 전체 대상자는 동질성 검정과 정규성 검증 방법 중 Kolmogorov-Smirnov test와 교차분석을 이용 하였다 $(\mathrm{p}>0.05)$. 대상자의 일반적 특성은 기술통계를 사용하였 으며, 모든 측정 자료들이 정규분포를 보였고, 정규분포를 보였기 때문에 모수적 검정법을 이용하여 평균값들의 비 교를 실시하였다. 집단 간 차이는 독립표본 t검정을 실시하 였으며, 각 군의 적용 전, 후간의 유의성을 비교하기 위하 여 대응표본 t검정을 실시하였다. 자료의 모든 통계학적 유 의수준은 $\alpha=0.05$ 로 설정하였다.

\section{연구 결과}

스마트폰 중독의 정도에 대한 변화를 알아보기 위해 성 인용 S-score를 측정하였다. 스마트폰 중동과 연관성 있는 $\mathrm{S}$-score에서는 tDCS그룹에서 실험 전, 후간 유의한 효과 를 보였으며 $(\mathrm{p}<0.001)$, 대조군에서도 유의한 효과를 보였 다 $(\mathrm{p}<0.05)$. 그룹간에는 $\mathrm{tDCS}$ 그룹이 더욱 효과적이었다 ( $\mathrm{p}<0.05$; 95\% CI: 0.702 - 4.922).

스트레스 정도에 대한 변화를 알아보기 위해 심박수와 피부전도도를 측정하였다. 심박수는 $\mathrm{tDCS}$ 그룹과 대조그 룹 모두 유의한 전과 후에서 유의한 차이를 보이지 않았고
( $>0.05)$, 그룹간에서도 유의한 효과를 보이지 않았다 ( $>0.05 ; 95 \%$ CI: $-3.390,-4.837$ ). 피부전도도는 tDCS그 룹에서 실험 전과 후에서 유의한 차이를 보였으며 $(\mathrm{p}<0.001)$. 그룹간에도 $\mathrm{tDCS}$ 그룹에서 더욱 유의한 효과를 보였다 ( $\mathrm{p}<0.05$; 95\% CI: 0.702 - 4.922).

\section{고찰}

스마트폰의 편리성과 함께 보급률이 높아짐으로써 스 마트폰 중독이 증가하고 있으며, 이 스마트폰 중독은 신체 적 장애로 시력 저하, 안구 건조증, 두통 증상과 손목터널 증후군, 어깨 통증 등이 발생할 수 있어 신체의 균형을 잃 게 한다[6,21]. 그렇기 때문에 많은 연구에서 스마트폰 중 독을 해소하기 위해 다양한 연구가 진행되어 왔으며, 본 연 구에서는 스마트폰 중독에 대한 $\mathrm{tDCS}$ 중재 효과를 알아보 고자 연구를 진행하였다. $\mathrm{tDCS}$ 를 적용한 그룹과 대조군 모두 유의한 효과를 보였으며, 그 중 tDCS그룹이 더욱 효 과적으로 나타났다 $(\mathrm{p}<0.05)$. Eichhammer 등 [17]의 연구 에 따르면 DLPFC에 고주파수로 자극했을 때 욕구가 줄어 든다고 하였다. George 등 [22]과 Olbrich 등 [15]의 연구 에 의에서도 DLPFC이 약물과 알코올에 대한 갈망증상에 주요한 효과를 보고하였으며, Eichhammer 등 [17]의 연구 에서는 DLPFC에 rTMS을 이용해 자극을 주면 흡연의 욕 구가 줄어든다고 발표했다. 이런 연구결과를 분석해 밨을

Table 2. Comparison of the Smartphone Addiction and Stress

$(\mathrm{n}=41)$

\begin{tabular}{|c|c|c|c|c|}
\hline Characteristics & & tDCS group $\left(n_{1}=21\right)$ & Control group $\left(\mathrm{n}_{2}=20\right)$ & $\mathrm{t}[95 \% \mathrm{CI}]$ \\
\hline \multicolumn{5}{|l|}{ Smartphone addiction } \\
\hline \multirow[t]{4}{*}{ S-Score (point) } & Baseline & $44.10(2.91)$ & $43.80(2.65)$ & 0.339 \\
\hline & Post & $39.33(3.62)$ & $41.85(3.87)$ & \\
\hline & Change & $4.76(3.25)$ & $1.95(3.23)$ & $2.696[0.702,4.922]^{\dagger}$ \\
\hline & $\mathrm{t}$ & $6.706^{* * *}$ & $2.546^{*}$ & \\
\hline \multicolumn{5}{|l|}{ Stress } \\
\hline \multirow{4}{*}{$\begin{array}{l}\text { Heart Rate } \\
\text { (beat/min) }\end{array}$} & Baseline & $74.42(9.89)$ & $75.40(8.44)$ & -0.343 \\
\hline & Post & $72.76(9.23)$ & $76.22(10.23)$ & \\
\hline & Change & $1.65(9.27)$ & $-0.82(9.27)$ & $0.853[-3.390,4.837]$ \\
\hline & $\mathrm{t}$ & 0.817 & -0.397 & \\
\hline \multirow{4}{*}{$\begin{array}{l}\text { Skin Conductance } \\
(\mu \mathrm{S})\end{array}$} & Baseline & $1.87(0.61)$ & $1.71(0.75)$ & 0.773 \\
\hline & Post & $1.07(0.70)$ & $1.61(0.75)$ & \\
\hline & Change & $0.80(0.88)$ & $0.10(1.14)$ & $2.696[0.702,4.922]^{\dagger}$ \\
\hline & $\mathrm{t}$ & $4.163^{* * *}$ & 0.397 & \\
\hline
\end{tabular}

Values are presented as mean $(\mathrm{SD})^{\mathrm{a}}$.

tDCS: transcranial direct current stimulation, CI: confidence interval.

Between the group $\left({ }^{\dagger} \mathrm{p}<0.05\right)$, With in the group $\left({ }^{*} \mathrm{p}<0.05,{ }^{* *} \mathrm{p}<0.01,{ }^{* * *} \mathrm{p}<0.001\right)$ 
때Addolorato 등 [23]의 연구에서 DLPFC를 자극하였 을 때 GABA (amma-aminobutyric acid)분비량을 향상 시켜 도파민 분비 조절에 효과적이라고 발표하였다. 이런 선행연구들을 바탕으로 분석해 밨을 때 tDCS가 DLPFC 를 자극하여 $\mathrm{GABA}$ 를 분비함으로써 도파민을 조절하고 스마트폰 욕구에 대한 갈망증상을 억제했다고 생각 할 수 있을 것이다. Moerman [24]에 의하면 플라시보 효과에 대 하여 오피오이드 모델을 설명하였는데 치료에 대한 신뢰 성을 갖는다면 편도체의 활성도가 높아지면서 옥시토신과 편도체의 수용체와 결합하여 오피오이드 관련 위약반응이 증가한다고 하였다. 대조군에서도 유의한 효과를 보였는 데 그 이유는 실험전에 스마트폰 중독에 관련된 실험임을 설명했기 때문에 그에 대한 플라시보 효과라고 생각된다.

Norris 등 [25]은 스트레스가 증가할수록 호흡과 심박수는 빨라지며, 피부전도도는 손의 땀에 의해 높아진다고 하였다. 선행연구를 바탕으로 스트레스를 측정하기 위해 심박수와 피 부전도도를 측정 하였다. 심박수는 유의한 변화를 가져오지 못하였으나, 피부전도도는 유의한 효과를 보였다 $(\mathrm{p}<0.05)$. Koob와Le Moal [26]는 약물의 남용과 같은 중독현상은 기능 적 동기부여 시스템과 관련된 안정성을 유지하기 위해 분자, 세포 및 신경회로과정을 시도하여 급성 스트레스를 촉진한다 고 하였다. 이런 선행연구를 종합해 봤을 때 스마트폰 중독으 로 인해 발생한 급성 스트레스가 감소하였고 손의 땀 분비의 감소로 피부전도도가 유의한 감소를 보인것으로 생각된다. 그 러나 심박수에 효과를 보이지 못한 이유는 심박수에 미치는 영 향적 요소들이 단순 신체적, 식이, 호흡 뿐 아니라 대상자의 컨 디션 및 단순 흥분에도 영향을 미칠 수 있기 때문에 유의한 효 과를 보이지 못한것으로 생각된다. 향후 연구에서는 더욱 다 분한 요소들을 통제하여 진행할 필요가 있다고 생각된다.

연구를 진행하는데 있어서 한계점은 대상자 선정에 있 어 더 많은 연령대를 확보하지 못하고 20대 초, 중반으로 구성한 부분으로 생각되며 추후 연구에서는 20대부터 6 , 70 대까지 다양한 연령으로 진행한다면 더욱 설득력 있는 연구가 될 수 있을 것으로 생각된다.

\section{결론}

성인을 대상으로 $\mathrm{tDCS}$ 를 적용하였고 스마트폰 중독과 스트레스의 변화를 알아보고자 하였다. 연구결과 $\mathrm{tDCS}$ 군 에서 스마트폰 중독과 스트레스 지표인 피부전도도에서 유의한 효과를 보였다.

본 연구를 통해 $\mathrm{tDCS}$ 를 활용하여 성인들에게 스마트폰 중독으로 인해 야기되는 신체적, 정신적 문제점을 감소 시 킬 수 있을 것이며, 또한 나아가 성인 뿐 아니라 청소년들 에게도 스마트폰 중독에 관련된 연구를 진행했을 때 보다 좋은 연구결과를 보일 수 있을 것이라고 생각된다.

\section{참고문헌}

1. Park HJ. Relationship between addict and use of application that teenagers use smartphone. Jeonju: Chonbuk National University Graduate School of Education; 2013.

2. Ministry of Science and ICT, National Information Society Agency. 2018 Smartphone Overdependence Survey. 2018.

3. Oh JH, Choi HC. Impact of Social Anxiety in Smartphone Use and Addiction : Focused on University Students. Broadcasting \& Communacation. 2017;18:37-78.

4. National Information Society Agency. 2018 Smartphone Overdependence Survey. 2011.

5. Kim BY, Ko EJ, Choi HI. A study on factors affecting smart-phone addiction in university students : A focus on differences in classifying risk groups. Studies on Korean Youth. 2013;24:67-98.

6. Hwang KH, Yoo YS, Cho OH. Smartphone Overuse and Upper Extremity Pain, Anxiety, Depression, and Interpersonal Relationships among College Students. The Journal of the Korea Contents Association. 2012;12:365-75.

7. Lee SJ. An Analysis on the Mental Health of Adolescent Addicted to Smartphone. Journal of Youth Welfare. 2018;20:47-67.

8. Ahn JA. A Study on the Smart phone Use Behavior and Addiction of University Students : Focused on Effect of Depression, Impulsivity and Interpersonal Relation, Campus Life. Journal of Communication Science. 2016;16:128-62.

9. Baumeister R, Heatherton T. Self-regulation failure: An overview. Psychol Inq. 1996;7:1-15

10. Sim MY, Lee DN, Kim EH. A Study on Influential Relations between Stress and Smartphone Addiction among College Students: With a Focus on the Mediating Effects of Depression and Self-Efficacy. Journal of Korea Academia-Industrial cooperation Society 2016;17:227-36.

11. Du YS, Jiang W, Vance A. Longer term effect of randomized, controlled group cognitive behavioural therapy for Internet addiction in adolescent students in Shanghai. Aust N Z J Psychiatry. 2010;44:129-34.

12. Kim S, Noh D. The Current Status of Psychological 
Intervention Research for Internet Addiction and Internet Gaming Disorder. Issues Ment Health Nurs. 2019;40:335-41.

13. Shin JH, Jang MK. Effect of group sandplay therapy to be addicted youth's addiction levels and anxiety. Symbols and sandplay therapy. 2016;7:39-45.

14. Uysal G, Balci S. Evaluation of a School-Based Program for Internet Addiction of Adolescents in Turkey. J Addict Nurs. 2018;29:43-9.

15. Olbrich HM, Valerius G, Paris C, Hagenbuch F, Ebert D, Juengling FD. Brain activation during craving for alcohol measured by positron emission tomography. Aust N Z J Psychiatry. 2006;40:171-8.

16. Addolorato G, Leggio L, Hopf FW, Diana M, Bonci A. Novel therapeutic strategies for alcohol and drug addiction: focus on GABA, ion channels and transcranial magnetic stimulation. Neuropsychopharmacology. 2012;37:163-77.

17. Eichhammer P, Johann M, Kharraz A, Binder H, Pittrow D, Wodarz N, et al. High-frequency repetitive transcranial magnetic stimulation decreases cigarette smoking. J Clin Psychiatry. 2003;64:951-3.

18. Lee JH, Kim SS, Yuh SS, Lee JH, Choi JH. Effect of Transcranial Direct Current Stimulation on Concentration of Attention. Journal of Korea Proprioceptive Neuromuscular Facilitation Association. 2013;11: 9-19.

19. Fukai M, Bunai T, Hirosawa T, Kikuchi M, Ito S, Minabe Y, et al. Endogenous dopamine release under transcranial direct-current stimulation governs enhanced attention: a study with positron emission tomography. Transl Psychiatry. 2019;9:115.

20. Lee JS, Kang DH, An HJ, Yoon DH, Jeong DU. Psychophysiological Characteristics of Chronic Pain Patients Measured by Biofeedback System

21. KOREAN ACADEMY OF SLEEP MEDICINE. 2009;16:79-84.

22. Yun JY, Moon JS, Kim MJ, Kim YJ, Kim HA, Huh BL, et al. Smart Phone Addiction and Health problem in University Student. Journal of Korean Association for Crisis and Emergency Management. 2011;3:92-104.

23. George MS, Anton RF, Bloomer C, Teneback C,
Drobes DJ, Lorberbaum JP, et al. Activation of prefrontal cortex and anterior thalamus in alcoholic subjects on exposure to alcohol-specific cues. Arch Gen Psychiatry. 2001;58:345-52.

24. Addolorato G, Leggio L, Hopf FW, Diana M, Bonci A. Novel therapeutic strategies for alcohol and drug addiction: focus on GABA, ion channels and transcranial magnetic stimulation. Neuropsychopharmacology. 2012;37:163-77.

24. Moerman DE. Edible symbols: The effectiveness of placebos. Ann. N. Y. Acad. Sci. 1981;364:256-68.

25. Norris SL, Lee C-T, Burshteyn D, Cea-Aravena J. The Effects of Performance Enhancement Training on Hypertension, Human Attention, Stress, and Brain Wave Patterns. J. Neurother. 2000;4:29-44.

26. Koob GF, Le Moal M. Drug addiction, dysregulation of reward, and allostasis. Neuropsychopharmacology. 2001;24:97-129. 